\title{
The Prevalence of Lower Extremity Peripheral Artery Disease among Adults with Type 2 Diabetes Mellitus Attending a Teaching Hospital in Ghana
}

\author{
Immanuel Amissah MD ${ }^{1}$, Emmanuel Kissiedu Antiri MBChB ${ }^{2}$ \\ ${ }^{1}$ Department of Internal Medicine \& Therapeutics, School of Medical Sciences, Cape Coast, Ghana. ${ }^{2}$ University of Cape Coast School of \\ Medical Sciences, Ghana
}

\begin{abstract}
Background: Peripheral artery disease (PAD) indicates generalized atherosclerosis and thus carries a very high risk for cardiovascular morbidity and mortality and is usually extensive and severe when associated with diabetes. Ankle Brachial Index (ABI) is a single, non-invasive and reliable bedside method for diagnosing the presence and severity of PAD. Objectives of the study was to estimate the prevalence of $P A D$ in the lower limbs among adult type 2 diabetic clients and to assess any associations between PAD and selected clinical factors like sex, age, hypertension and duration of diabetes. Methods: A cross-sectional descriptive study was conducted between January, 2015 through April, 2015 among patients with diabetes attending the diabetes clinic at Cape Coast teaching hospital, Ghana. A pre-coded questionnaire was used to collect data by face to face interview, and ABI measurement was done for each client. An ABI of $<0.9$ was considered diagnostic of PAD. Results: A total of 200 adult clients with diabetes with a female predominance (71.5\% females; $28.5 \%$ males) participated in the study. Majority were within the 50-59 and 60-69 age groups. Majority (34.5\%) of the clients reported duration of their diabetes diagnosis between 5-10 years. The prevalence of PAD among the study clients on the right and left lower limbs were $17.5 \%$ and $18.0 \%$ respectively with preponderance in female clients. Of these, $22 / 35(62.9 \%)$ had mild PAD on the right leg and 24/36 (66.7\%) on the left leg whiles 13/35 (37.1\%) had moderate PAD on the right leg and 12/36 (33.3\%) on the left leg respectively with no severe disease noted. PAD was associated with duration of diabetes $(p<0.05)$. Majority $(88.5 \%)$ of the clients had hypertension co-morbidity. Conclusions: PAD is common among adult type 2clients with diabetes in Ghana and early screening and treatment by medical professionals needs to be emphasized to help lower subsequent morbidity and mortality and systemic atherosclerotic diseases.
\end{abstract}

Keywords: Peripheral artery disease, Type 2 diabetes, Ankle brachial index, Ghana, Cape Coast

\section{Introduction}

Peripheral artery disease (PAD) is a condition characterized by atherosclerotic occlusive disease of the lower extremities ${ }^{1}$ and is one of the macrovascular complications highly prevalent in adult diabetic patients. Diabetes and smoking are the strongest risk factors for PAD, and other well known risk factors of PAD are advanced age, hypertension and hyperlipidemia $^{2}$. Also in people with diabetes, the risk of PAD is found to increased by age, duration of diabetes, and presence of peripheral neuropathy ${ }^{1}$.

In Ghana, the prevalence rate of diabetes mellitus in adults is 3.3 per cent $^{3}$ and the prevalence of PAD worldwide has been estimated at between $4.5 \%$ and $29 \%^{4}$, and in Sub Saharan Africa, the prevalence of PAD varies from 1.7-52.5\% $\%^{5-8}$. A study in Nigeria reported evidence of PAD in 54\% of diabetic patients with foot complications ${ }^{9}$, whilst another study from Tanzania found PAD in $21 \%$ of diabetic patients ${ }^{10}$.

Screening for PAD is important for two main reasons. Firstly, the majority of patients with PAD are asymptomatic, even in symptomatic patients atypical symptoms are common $^{11,12}$. Secondly, PAD indicates generalized atherosclerosis and thus carries a very high risk for cardiovascular morbidity and mortality ${ }^{13,14}$. PAD is also usually extensive and severe when associated with diabetes ${ }^{15}$.Therefore, early screening, detection and optimal management of asymptomatic PAD among the adult diabetic clients would significantly lower subsequent morbidity and mortality and systemic atherosclerotic diseases.
Ankle Brachial Index (ABI), which is the ratio of ankle to brachial systolic blood pressure is a simple, non-invasive and reliable bedside method for diagnosing the presence and severity of PAD. It is $95 \%$ sensitive and $100 \%$ specific compared to the gold standard angiography ${ }^{16}$. American College of Cardiology /American Heart Association (ACC/AHA) also recommend measurement of ABI in symptomatic patients as a diagnostic criterion ${ }^{17}$. An ABI of less than 0.9 is diagnostic of PAD. In Ghana, there are no studies examining the burden of PAD and related clinical factors in adult diabetic clients. We therefore conducted this descriptive cross sectional study among adult diabetic clients attending the diabetic outpatient clinic of Cape Coast teaching hospital, Ghana to determine the prevalence of lower extremity PAD among type 2 diabetic clients. The objectives of the study were to 1) to estimate the prevalence of PAD in the lower limbs among adult type 2 diabetic clients and 2) to assess any associations between PAD and selected clinical factors like sex, gender, hypertension and duration of diabetes.

\section{Materials and Methods}

\section{Study setting}

This study was conducted at the diabetic outpatient clinic of Cape Coast teaching hospital, Cape Coast, Ghana. The hospital is a tertiary referral hospital and the diabetes specialist clinic is where new and old diabetic patients are reviewed once a month, and there are 3 clinic days in a week and an average of 40 old patients and 2 new patients are seen every clinic day. The clinic is run by two medical officers, one physician specialist, five nurses and two dietitians. 


\section{International Journal of Science and Research (IJSR) \\ ISSN (Online): 2319-7064}

Index Copernicus Value (2013): 6.14 | Impact Factor (2015): 6.391

Study design

The study was a cross-sectional prospective survey that was conducted between January, 2015 through April, 2015.

\section{Study population and sampling procedure}

The study population consisted of type 2 adult diabetic clients aged $>40$ years who are registered patients at the clinic. Clients excluded from the study included those below 40 years of age, clients who have smoked or consumed tea or coffee hours prior to their clinic appointment, those with lower limb amputations and those who withheld consent for the study. Systematic random sampling was used to recruit clients into the study. This was done by choosing the 3rd patient as they were triaged during their review clinic day. In case the client declined to participate in the study or was ineligible, the next one was selected. This was done during every clinic day until the desired sample size was attained. A convenience sample size of 200 clients was used in this study.

\section{Data collection}

A pre-coded questionnaire were used to collect the study information which included: socio- demographic characteristics (age, gender, educational level, occupation, religion, ethnicity) and clinical history (age at initial diagnosis of DM, duration of DM, smoking history and history of hypertension). The questionnaire was administered to the study participants after offering informed consent by the same trained research assistant by face to face interview during their routine clinic reviews.

\section{Measurement of ABI}

For all patients, we measured the brachial systolic blood pressure after a 5-minute rest in the supine position, using a mercury sphygmomanometer (Model number 1002 by Riester, Germany). To measure the brachial systolic blood pressure, the brachial artery was palpated and identified in each arm. The brachial systolic blood pressure was then determined by applying the blood pressure cuff with the lower edge at $2.5 \mathrm{~cm}$ above the ante-cubital fossa and inflated to at least $30 \mathrm{mmHg}$ above the level at which radial pulsation disappeared so as to ensure complete collapse of the brachial artery. The cuff deflation proceeded slowly at no greater than $2 \mathrm{mmHg}$ per second. As the cuff was being deflated slowly the research assistant listened for the first korotkoff sound with a littman Stethoscope (3M Littmann Cardiology III Stethoscope, U.S.A) placed over the brachial artery in the ante-cubital fossa. The brachial systolic blood pressure was measured in both arms, two times in each arm and the mean was calculated for each arm and the higher value is used as the denominator of the ABI.

Ankle systolic blood pressures for each lower limb was also measured using the same mercury sphygmomanometer while using a standardized Doppler ultrasonic device (8 MHz; Edan ${ }^{\mathrm{TM}}$ SonoTrax ${ }^{\circledR}$ ED 120114321; Shekou, China) to accentuate the sounds over the posterior tibial and dorsalis pedis arteries. At each ankle, the posterior tibial artery was palpated, and the cuff was applied at about $2 \mathrm{~cm}$ above the ankle (medial malleoli) and inflated to at least $30 \mathrm{mmHg}$ above when the Doppler could not detect any sounds. Cuff deflation was then proceeded slowly, no greater than 2 $\mathrm{mmHg}$ per second and the ankle systolic blood pressure was taken at the point at which the first Doppler signal appeared during deflation of the cuff. This was done two times and the mean calculated. The same procedure was then used to measure the systolic blood pressure at the dorsalis pedis artery and the higher value is the numerator of the ABI in each limb

The ankle-brachial index for each lower limb was calculated by dividing the higher of two mean systolic blood pressure readings at the ankle (i.e., one from the dorsalis pedis or from the posterior tibial artery) by the higher of the two mean brachial systolic blood pressure readings. For all clients, measurements on both lower limbs were obtained, and the lower value was considered as the patient's ABI. $\mathrm{ABI} \leq 0.9$ was considered diagnostic of PAD.

\section{Ethical Considerations}

All patients gave written informed consent to participate in the study and the study was approved by the community medicine department, College of Allied and Health Sciences, University of Cape Coast, Ghana as dissertation in partial fulfillment of the $\mathrm{MB}$ ChB program in 2015. Approval was also given by management of the hospital to conduct the study at the hospital.

\section{Study definitions}

$\mathrm{PAD}$ was defined as an $\mathrm{ABI} \leq 0.9$. The diagnostic criteria for PAD based on the ABI were interpreted as follows ${ }^{1}$ :

- Normal if 0.91-1.30

- Mild obstruction if $0.70-0.90$

- Moderate obstruction if 0.40-0.69

- Severe obstruction if $<0.40$

- Poorly compressible if $>1.30$

Hypertension was defined as a blood pressure of $\geq 140 / 90$ $\mathrm{mmHg}$ with diagnosis of diabetes or chronic kidney disesse $\mathrm{OR} \geq 150 / 90$ if age $<60$ years with no diabetes or chronic kidney disease OR $\geq 160 / 90$ if age $>60$ years with no diabetes or chronic kidney disease ${ }^{18}$ OR being on hypertensive medications. We defined diabetes as a fasting glucose level $\geq 7.0 \mathrm{mmol} / \mathrm{L}^{19}$ on two consecutive times, or taking medication for diabetes.

\section{Statistical Analysis}

Data were analyzed by using SPSS software version 19 (SPSS Inc, Chicago). Chi-squared test was used to assess the association between ABI and the following selected factors: age, gender, history of hypertension, and duration of diabetes. A p-value of less than 0.05 was considered statistically significant. The results for the descriptive statistics were presented using frequency tables.

\section{Results}

\section{Demographics of Study Clients}

A total of 200 adult diabetic clients with female predominance $(71.5 \%$ females; $28.5 \%$ males) participated in the study (Table 1). Majority of the clients were within the 50-59 and 60-69 age groups. The highest educational level attained by the clients were Junior high school (38.0\%), followed by no education $(24.5 \%)$. The predominant ethnic group was Fante $(65.3 \%)$, followed by Twi $(23.1 \%)$.

\section{Volume 5 Issue 6, June 2016 www.ijsr.net}




\section{International Journal of Science and Research (IJSR) \\ ISSN (Online): 2319-7064}

Index Copernicus Value (2013): 6.14 | Impact Factor (2015): 6.391

Clinical history of Study Clients

Majority $(34.5 \%)$ of the clients reported duration of their diabetes diagnosis between 5-10 years. Majority (88.5\%) of the clients were also diagnosed with hypertension (Table 2). Majority (98.0\%) also reported no smoking history.

\section{Prevalence of PAD}

The prevalence of PAD among the study clients on the right and left lower limbs were $17.5 \%$ and $18.0 \%$ respectively (Table 3). Majority had mild-moderate obstruction, with no severe obstruction obtained (Table 4).

\section{Association between PAD and Clinical factors}

Table 5 presents the association between PAD and selected clinical factors such as age, gender, hypertension and duration of diabetes. PAD was common among the 60-69 age group in both lower limbs. Prevalence was also high among the female clients, but with no statistically significance between PAD and sex. Prevalence of PAD was higher with increasing duration of diabetes with a significant association between PAD and duration of diabetes $(\mathrm{p}=0.035$ in right lower limb and 0.037 in left lower limb) respectively. There was also a high prevalence of PAD among study clients with hypertension $(91.4 \%$ in right leg and $94.4 \%$ in left leg) respectively.

Table 1: Socio-demographic characteristics of study

\begin{tabular}{|l|c|}
\multicolumn{2}{|c|}{ client's. } \\
\hline Age (years): & Frequency $(\%)$ \\
$40-49$ & \\
$50-59$ & $45(22.5)$ \\
$60-69$ & $71(35.5)$ \\
$70-79$ & $59(29.5)$ \\
Sex: & $25(12.5)$ \\
Male & \\
Female & $57(28.5)$ \\
Religion: & $143(71.5)$ \\
Christian & $182(91.9)$ \\
Muslim & $15(7.6)$ \\
Traditional & $1(0.5)$ \\
Marital Status: & $1(0.5)$ \\
Single & $142(71.0)$ \\
Married & $23(11.5)$ \\
Divorced & $34(17.0)$ \\
Widowed & \\
Educational level: & $49(24.5)$ \\
No education & $24(12.0)$ \\
Primary & $76(38.0)$ \\
JHS/Middle & $25(12.5)$ \\
SHS/Vocational & $23(11.5)$ \\
Tertiary/Polytechnic & $3(1.5)$ \\
Post-graduate & \\
Ethnicity: & $46(23.1)$ \\
Twi & $130(65.3)$ \\
Fante & $10(5.0)$ \\
Ewe & $3(1.5)$ \\
Ga Adangme & $10(5.0)$ \\
Hausa & $9(4.5)$ \\
Occupation: & $33(16.5)$ \\
Civil servant & $61(30.5)$ \\
Public servant & $1(0.5)$ \\
Retired & $96(48.0)$ \\
Student & Other \\
\hline
\end{tabular}

*Other includes: farmers; fishermen; fishmongers and petty traders
JHS: Junior high school; SHS: Senior high school

Table 2: Clinical history of Study Participants

\begin{tabular}{|l|l|}
\hline \multicolumn{1}{|c|}{ Variables } & Frequency (\%) \\
\hline Duration of Diabetes (yrs): & \\
$<1$ & $19(9.5)$ \\
$1-4$ & $67(33.5)$ \\
$5-10$ & $69(34.5)$ \\
$11-15$ & $25(12.5)$ \\
$>15$ & $20(10.0)$ \\
History of Smoking: & $4(2.0)$ \\
Yes & $196(98.0)$ \\
No & \\
Hypertension diagnosis: & $177(88.5)$ \\
Yes & $23(11.5)$ \\
No & \\
\hline
\end{tabular}

Table 3: Prevalence of PAD in right and left lower legs

\begin{tabular}{|c|c|c|}
\hline Variable & $\begin{array}{c}\text { Right lower leg } \\
\mathrm{n}(\%)\end{array}$ & $\begin{array}{c}\text { Left lower leg } \\
\mathrm{n}(\%)\end{array}$ \\
\hline Normal & $165(82.5)$ & $164(82.0)$ \\
\hline PAD $(\mathrm{AB} 1<0.9)$ & $35(17.5)$ & $36(18.0)$ \\
\hline Total & $200(100.0)$ & $200(100.0)$ \\
\hline
\end{tabular}

Table 4: Severity of PAD in both legs

\begin{tabular}{|c|c|c|}
\hline Severity & $\begin{array}{c}\text { Right lower leg } \\
\mathrm{n}(\%)\end{array}$ & $\begin{array}{c}\text { Left lower leg } \\
\mathrm{n}(\%)\end{array}$ \\
\hline Mild (ABI 0.70-0.90) & $22(62.9)$ & $24(66.7)$ \\
\hline Moderate (ABI 0.40-0.69) & $13(37.1)$ & $12(33.3)$ \\
\hline Severe $(\mathrm{ABI}<0.40)$ & $0(0.0)$ & $0(0.0)$ \\
\hline
\end{tabular}

Table 5: Association between PAD and selected clinical

\begin{tabular}{|l|c|c|}
\hline \multicolumn{4}{|c|}{ factors } \\
\hline Aariables & $\begin{array}{c}\text { PAD(Right leg) } \\
n(\%)\end{array}$ & $\begin{array}{c}\text { PAD (Left leg) } \\
\mathrm{n}(\%)\end{array}$ \\
\hline $40-49$ & $9(25.7)$ & $7(19.4)$ \\
$50-59$ & $6(17.1)$ & $7(19.4)$ \\
$60-69$ & $11(31.4)$ & $14(38.9)$ \\
$70-79$ & $9(25.7)$ & $8(22.2)$ \\
\hline p-value & 0.285 & 0.147 \\
\hline Sex: & $14(40.0)$ & $13(36.1)$ \\
Male & $21(60.0)$ & $23(63.9)$ \\
Female & 0.068 & 0.300 \\
\hline p-value & $32(91.4)$ & $34(94.4)$ \\
\hline Hypertension: & $3(8.6)$ & $2(5.6)$ \\
Yes & 0.544 & 0.281 \\
No & $4(11.4)$ & $3(8.3)$ \\
\hline p-value & $4(11.4)$ & $4(11.1)$ \\
\hline Duration of Diabetes (yrs): & $7(20.0)$ & $7(19.4)$ \\
<1 & $10(28.6)$ & $12(33.3)$ \\
$1-4$ & $10(28.6)$ & $10(27.8)$ \\
$5-10$ & 0.035 & 0.037 \\
$11-15$ & & \\
$>15$ & &
\end{tabular}

\section{Discussion}

Diabetes mellitus is a rapidly growing public health problem in Ghana and there is a strong association of PAD with diabetes. The objectives of the study were to 1) to estimate the prevalence of PAD in the right and left lower limbs among adult type 2 diabetic clients and 2) to assess any associations between PAD and selected clinical factors like sex, gender, hypertension and duration of diabetes.

Volume 5 Issue 6, June 2016 www.ijsr.net 


\section{International Journal of Science and Research (IJSR) \\ ISSN (Online): 2319-7064}

Index Copernicus Value (2013): 6.14 | Impact Factor (2015): 6.391

In this study, we enrolled 200 adult type diabetic clients with $146(71.5 \%)$ female predominance. Thirty-five clients $(17.5 \%)$ had PAD (ABI $<0.90$ on the right leg and 36 $(18.0 \%)$ on the left leg respectively. Of these, 22/35 (62.9\%) had mild PAD on the right leg and 24/36 (66.7\%) on the left leg whiles $13 / 35(37.1 \%)$ had moderate PAD on the right leg and $12 / 36(33.3 \%)$ on the left leg respectively. Amongst those with PAD, no one had severe disease. The findings of majority of our study clients having mild PAD is similar to a study in Uganda by Okello et $\mathrm{al}^{20}$ which showed a PAD prevalence of $24 \%$, of which majority $(87.27 \%$ ) had mild PAD. This high prevalence of mild PAD in our study could be due to the very low rate of smoking $(2.0 \%)$ and shorter duration of diabetes $<10$ years among the study clients. The prevalence of PAD in our study is within the range of several studies done in Sub-Saharan Africa that used a similar screening technique ${ }^{5}$. Prevalence of PAD was higher in females than males in our study because most of the diabetic clients were females as shown in the demographic data, but no statistically significant association was found between PAD and sex in our study. But other studies have reported an association of PAD with female sex ${ }^{21}$.

PAD progresses more rapidly in diabetics and its prevalence also increases with age and the duration of diabetes ${ }^{22}$. This was evident in our study with a statistically significance $(\mathrm{p}<0.05)$ between PAD with duration of diabetes, however there was no statistically significant association between PAD and age in our study. A study in Nigeria by Oyedale et al also showed that PAD was associated with age, sex and marital status ${ }^{6}$.

Studies have also reported an association of PAD with hypertension $^{23}$ and in our study, although the prevalence of PAD was higher among clients with hypertension, there was no significant association between PAD and hypertension. In another multi-racial cross sectional study performed in Malaysia, Asia to determine the prevalence of ABI in 200 diabetic patients at a primary care setting, the overall prevalence of PAD was $16 \%$ in this diabetic population. The prevalence of PAD was $5.8 \%$ in Malaysia, $19.4 \%$ in Chinese and $19.8 \%$ in Indians. However, no significant relationships were found between age, gender, smoking status, duration of diabetes mellitus, hypertension, dyslipidemia, and $\mathrm{PAD}^{24}$.

\section{Conclusions}

This study documents a high prevalence of PAD among adult Ghanaian patientswith diabetes and early screening using $\mathrm{ABI}$ and treatment by medical professionals needs to be emphasized to help lower subsequent morbidity and mortality and systemic atherosclerotic diseases.

\section{Conflict of Interest}

None declared.

\section{References}

[1] Peripheral Arterial Disease in People with Diabetes. American Diabetes Association. Diabetes care 2003; 26(12): 3333-41.
[2] Criqui M (2001) Peripheral arterial disease: epidemiological aspects. Vascular Medicine 6: 3-7.

[3] International Diabetes Federation Atlas. $6^{\text {th }}$ Edition Update, IDF, 2014.

[4] Paul A, Mash B, Rupesinghe G (2007) Peripheral arterial disease - high prevalence in rural black South Africans. S Afr Med J 97: 285-288.

[5] Kengne A, Amoah A, Mbanya J (2005) Cardiovascular Complications of Diabetes Mellitus in Sub-Saharan Africa. Circulation 112: 3592-3601.

[6] Oyelade BO, OlaOlorun AD, Odeigah LO, Amole IO, Adediran OS. The prevalence of peripheral arterial disease in diabetic subjects in southwest Nigeria. Afr J Prm Health Care Fam Med. 2012;4 (1), 354

[7] Gulam-Abbas Z, Lutale J, Morbach S, Archibald L (2002) Clinical outcome of diabetes patients hospitalized with foot ulcers, Dar es Salaam, Tanzania. Diabet Med 19: 575-579.

[8] Rheeder P, van-Wyk J, Stolk R, Grobbee D (2004) Assessing peripheral arteries in South African black women with type 2 diabetes mellitus. S Afr Med J 94: 379-383.

[9] Abbas ZG, Archibald LK. Foot complicationsin diabetic patients with symptomatic peripheral neuropathy in Dar es Salaam, Tanzania. Diabetes Int2000; 10: 52-6.

[10] Abbas ZG, Lutale JK, Morbach S, Archibald LK. Clinical outcome of diabetes patients hospitalized with foot ulcers. Diabetic Medicine2002; 19: 575-9.

[11] Hirsch AT, Criqui MH, Treat-Jacobson D, et al. Peripheral Arterial Disease Detection, Awareness, and Treatment in Primary Care. JAMA 2001; 286(11): 1317-24.

[12] Makdisse M, Pereira Ada C, Brasil Dde P, et al. Prevalence and Risk Factors Associated with Peripheral Arterial Disease in the Hearts of Brazil Project. Arq Bras Cardiol 2008; 91(6): 370-82.

[13] Norman PE, Davis WA, Bruce DG, et al. Peripheral Arterial Disease and Risk of Cardiac Death in Type 2 Diabetes. The Fremantle Diabetes Study. Diabetes Care 2006; 29(3): 575-80.

[14] Li J, Luo Y, Xu Y, et al. Risk Factors of Peripheral Arterial Disease and Relationship between Low Ankle-Brachial Index and Mortality from All-Cause and Cardiovascular Disease in Chinese Patients with Type 2 Diabetes. Circ J 2007; 71(3): 377-81.

[15] Jude EB, Oyibo SO, Chalmers N, et al. Peripheral Arterial Disease in Diabetic and Nondiabetic Patients. A Comparison of Severity and Outcome. Diabetes Care 2001; 24(8):1433-7.

[16] American Diabetes Association Position statementStandards of Medical Care in Diabetes. Diabetes Care 37: S14-S80.

[17] Hirsch AT, Haskal ZJ, Hertzer NR, et al. ACC/AHA 2005 Guidelines for the Management of Patients with Peripheral Arterial Disease (Lower Extremity, Renal, Mesenteric, and Abdominal Aortic): Executive Summary a Collaborative Report from the American Association for Vascular Surgery/Society for Vascular Surgery, Society for Cardiovascular Angiography and Interventions, Society for Vascular Medicine and Biology, Society of Interventional Radiology, and the ACC/AHA Task Force on Practice Guidelines 


\section{International Journal of Science and Research (IJSR) \\ ISSN (Online): 2319-7064}

Index Copernicus Value (2013): 6.14 | Impact Factor (2015): 6.391

(Writing Committee to Develop Guidelines for the Management of Patients with Peripheral Arterial Disease) Endorsed by the American Association of Cardiovascular and Pulmonary Rehabilitation; National Heart, Lung, and Blood Institute; Society for Vascular Nursing; TransAtlantic Inter-Society Consensus; and Vascular Disease Foundation. J Am Coll Cardiol2006; 47(6): 1239-312.

[18] James PA., Oparil S., Carter BL., et al.2014. Evidencebased guideline for the management of high blood pressure in adults: report from the panel members appointed the Eight Joint National Committee (JNC 8). JAMA 2014; 311(17): 1809

[19] Genuth S, Alberti KG, Bennett P, et al., Expert Committee on the Diagnosis and Classification of Diabetes Mellitus. Follow-up report on the diagnosis of diabetes mellitus. Diabetes Care 2003;26: 31603167

[20] Okello S.,Millard A., Owori,R., Bambeiha Asiimwe S.,Jacob Siedner M., Rwebembera J.,Wilson LA., Moore CC., Herb Annex B.Prevalence of lower extremity Peripheral artery disease among adult diabetes patients in Southwestern Uganda BMC Cardiovascular Disorders 2014, 14:75

[21] Aboyans V., Criqui MH., McClelland RL., Allison MA., McGrae McDermott M., Goff DC., Manolio TA: Intrinsic continuation of gender and ethnicity to normal ankle-branchial index values: the Multi-Ethnic Study of Atherosclerosis (MESA). J Vasc Surg 2007, 45 (20:319-327

[22] Donnelly R. Evidence-based symptom relief of intermittent claudication: efficacy and safety of cilostazol. Diab Obs Metab 2002; 4: S20-5

[23] Guerchet M., Aboyans V., M' Belesso P., Mohanya AM., Salazar J., Bandzouzi B; Tabo A., Lacroix P., Preux D-M: 241 Particularities of the epidemiology of lower extremities peripheral artery disease in central Africa. Arch Cardiovasc Dis Supplements 2010, 2(1):77

[24] Rabia K, Khoo E (2007) Prevalence of Peripheral Arterial Disease in Patients with Diabetes Mellitus in a Primary Care Setting. Med J Malaysia 62:130-133.

\section{Author Profile}

IA was the principal author and contributed to the study concept, design and interpretation and discussion of data. EKA contributed to the data collection and analysis of the data. 